\title{
Mobile-Assisted Language Learning Application for English Intensive Course
}

\author{
Manda Rohandi \\ Informatics Engineering \\ Faculty of Engineering, UNG \\ Gorontalo \\ Manda.rohandi@ung.ac.id
}

\author{
Nurlaila Husain, Indri W. Bay \\ English Language Education \\ Faculty of Language and Culture, UNG \\ Gorontalo \\ indri_wirahmi@yahoo.com
}

\begin{abstract}
Mobile-assisted language learning (MALL) is the new generation of e-learning. It deals with the use of mobile technology in language learning. The aims of this research is to develop a MALL application as additional media for English intensive course textbook, that help students to understand the course materials both inside and outside classroom using mobile devices. This research used $R \& D$ method with 5 steps, start with 1) identification of IC textbook; 2) product development; 3) product validation; 4) application feedback; and end with 5) product review. The result shown, that the application of MALL for English intensive course is very useful and helpful as a supplement for the IC textbook. The student can use the application both inside and outside the classroom (mobile), so it could give impact on increasing student motivation in understanding the materials. In addition, the application is able to control the users that login to the application as a prevention to the irresponsible user that violated copyright of this application.
\end{abstract}

\section{Keywords-MALL, English Intensive Course}

\section{INTRODUCTION}

As one of a specific subject that taught in English department, Intensive Course (IC) has 12 credits that must be enrolled at semester I. IC aims to prepare the students to have a higher level of English knowledge for the next semester. The course has always been attention for the lecturer in order to develop their learning process in terms of teaching method, materials and learning media. IC covered the language skills (speaking, writing, reading and listening) and language components (grammar, vocabulary and pronunciation), and displayed thematically. The students only have two opportunities to join this program and if they fail then they have to transfer to other departments.

In the process of teaching IC, the lecturers found that the textbook was not enough for the students to learn IC because they only studied when they were in the classroom. Even though the lecturing was conducted 3-4 days in a week (a meeting equals $4 \mathrm{SKS}$ ), still the students felt difficulties to study the whole topics in IC. Ideally, a textbook should be completed by an interactive learning media. Definitely, learning English as a foreign language needs additional learning media, which is attractive and interactive to increase students' motivation. Besides, the use of an interactive media will create more interesting learning situation.

In previous research by Rohandi et al (2016) [1], has develop a web-based computer assisted language learning (WBCALL) application for English IC as a learning media to complete IC textbook in order to increase students' motivation in learning English and to create more enjoyable learning atmosphere. This application is the type of "Do what I tell you" application, which is an application that controls the student activities in drills, exercises, quizzes, and tests, and then the application will notify the answer is correct or incorrect. The application consists of 7 major themes with 4 language skills. The trial result of WBCALL application to English department students showed that the use of WBCALL application in learning IC is very useful and helpful in understanding the material, because the presence of WBCALL application, students could learn IC material both inside and outside the classroom, so that could impact on increasing students motivation in IC learning. The drawback of this application is that only run in the desktop computer or laptop which has a large size, making it difficult while in mobile condition. Reference to these constraint, it is necessary to develop a learning application based on mobile-assisted language learning (MALL). MALL is a subset of e-learning where it deals with the use of mobile technology in language learning. The application to be developed has to have the ability to update it content dynamically in case of changes or updates of the materials. In addition, it should able to control the users to prevent violation of copyright by the irresponsible users.

\section{LITERATURE REVIEW}

\section{A. English Intensive Course Textbook}

The IC textbooks comprised language skills (speaking, writing, reading and listening) and language components (grammar, vocabulary and pronunciation). IC textbook covers 7 major topics. Each topic will be identified and chosen as a content of MALL containing language skills and language components. In the process of teaching IC, the lecturers found that the textbook was not enough for the students to learn IC because they only studied when they were in the classroom. Even though the lecturing was conducted 3-4 days in a week (a 
meeting equals $4 \mathrm{SKS}$ ), still the students felt difficulties to study the whole topics in IC. Ideally, a textbook should be completed by an interactive learning media. Definitely, learning English as a foreign language needs additional learning media, which is attractive and interactive to increase students' motivation. Besides, the use of an interactive media will create more interesting learning situation.

\section{B. Mobile-Assisted Language Learning (MALL)}

For the first time when the mobile device is invented in 1973, no one thought that mobile technology could change the way of people live. The rapid development of mobile technology that almost compete the ability of desktop computer in software and hardware, feels capable of being used as a tool in language learning. Today, mobile device such as smart phone and tablet could do anything, start with basic functionalities (phone call or SMS), to advances ability (game, browsing, shopping, etc.), has given advantages in education and language learning.

Miangah and Nezarat, explained that MALL is related with the use of mobile technology in language learning [2]. According to Huang, et al, there are two characteristic of mobile device, portability and connectivity [3]. In connectivity, mobile system development has to have capability to connect to the learning website using mobile device wireless, to access the learning material anywhere, including usage of SMS and mobile e-mail. Kloper et al [4], established the superiority of mobile device as follows: 1) Portability, where the device could be taken to a different place with small size and shape; 2 ) Social interactivity, data exchange and collaboration with other students is possible through mobile device; 3) sensitivity context, data in mobile device can be collected and responded specifically with current time and location; 4) Connectivity, mobile device can be connected with other devices, the devices to collecting data, or the existing network to create a sharing network; 5) Individualities, activity from platform can be customized for individual learner.

The learning technology based on mobile, is very useful in doing activities outside the classroom. These activities enable learning to be directly connected to real-world experiences. Moreover, learning through mobile device outside the classroom has a better advantage in exploiting leisure time of the students even the mobile persons can still improve their language skill [5]. However, learning through mobile devices has the disadvantage of small screen size that makes the learners difficult to read the material. Because of these limitations, some people prefer to use desktop PCs compared to mobile devices.

\section{RESEARCH METHODOLOGY}

In this research we used a Research and Development (R\&D) method. This method is used to produce certainty product and to test the effectiveness of the product [6]. The steps of R\&D method described in the Figure 1.

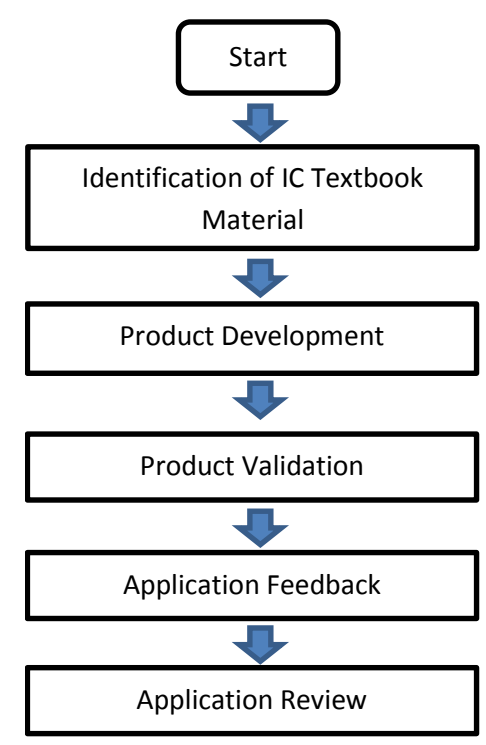

Fig. 1. Steps of R\&D method

\section{RESULT AND DISCUSSION}

\section{A. Identification of IC Textbook Material}

The textbook are consists with 7 major themes with 5 sub themes. Each topic will be identified and chosen as a content of MALL containing language skills (except for writing and speaking skills) and language components. Content selection involves researchers and lecturers. It is completed by tasks and their answers. Moreover, questionnaire as a research instrument was given to the 20 students of IC program. It aimed to find out the effectiveness of MALL and students' responses towards the quality of MALL.

\section{B. Product Development}

The steps of product development are described as follow:

- Use Case Modelling as a System Design

Use case modelling is a set of diagrams and texts describing how the user interacts with the system [7]. In addition, this operates to analyze the functional need of system [8]. The type of application that created is adopts the type of "Do what I tell you" application by WBCALL. Through this, the students have to follow the application's commands. It controls students' activities to finish tasks and quizzes and let them know whether the answers are right or wrong. In this application, actor refers to the student. Through this, the students have to follow the application's commands. It controls students' activities to finish tasks and quizzes and let them know whether the answers are right or wrong. In this application, actor refers to the student. It has 8 use case; they are for listening IC audio, answering questions, checking answers, reading IC English texts, logging in to the system, checking users, and update IC materials. Use case diagram of MALL is shown on figure 1 . In use 
case diagram system of MALL, the students can log in to the system and the system will check on SIAT system whether the student is enrolls the course or not. If the students are not enrolls the course then the system will not enter the application. This prevents the irresponsible users to use the application. The students can also listen or read IC material before answering questions. They also have a chance to check answers. In addition they can update materials if there any changes or update to the materials.

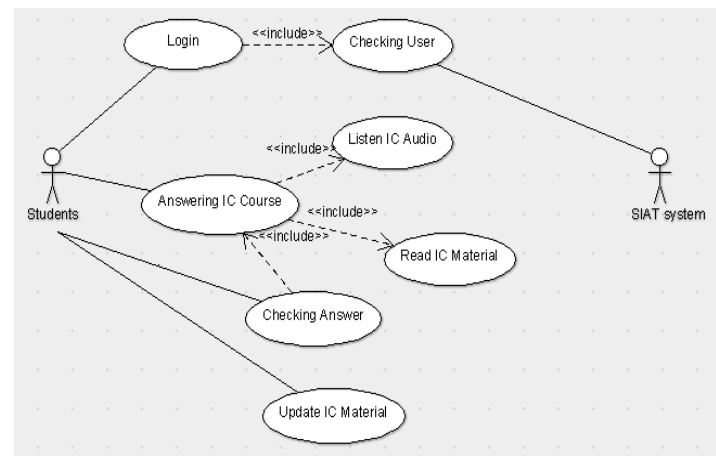

Fig. 2. Use case Diagram of MALL

- $\quad$ The Implementation of MALL system

The system is developed in android studio using java and $\mathrm{xml}$ programming language. Next figures show the display of system GUI. Before using the application, student have to login by typing their name and password firstly. The system then check username and password are they match with students that register to the English IC in SIAT system. Figure 3 shows user's login form.

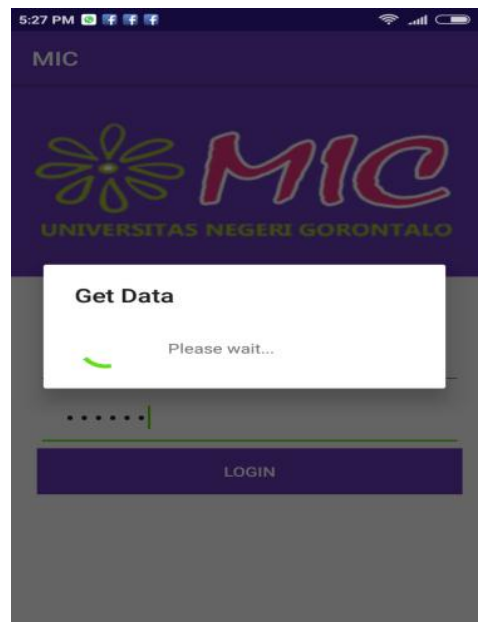

Fig. 3. User Login Form

If the login process success, then the menu form will appears. The menu form consists of 7 major themes with 5 sub themes contain language skills (except for writing and speaking skills) and language components. The users could choose one of the themes by click it (shown in figure $4 a$ ). If we click one of the themes form, then the category form will appears (shown in figure $4 b$ ).

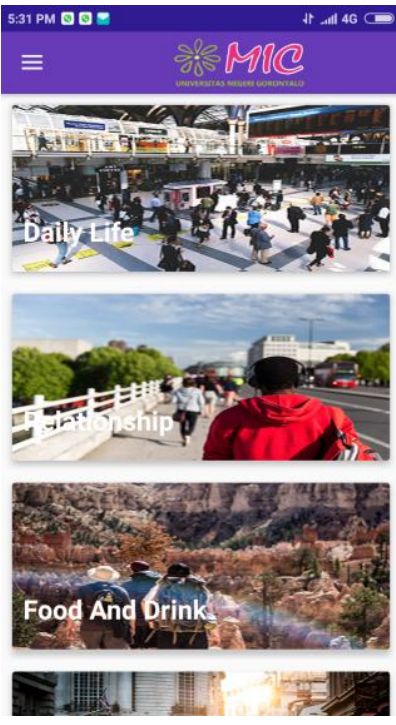

(a)

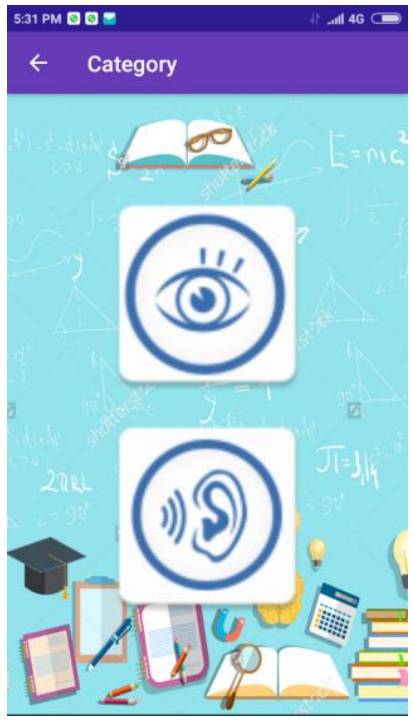

(b)
Fig. 4. (a) Themes menu, (b) sub Themes menu

The category form contains reading and listening skills. If one of the categories was clicked, as an example reading, then the form that contains sub themes will appears, as shown in Figure 5.

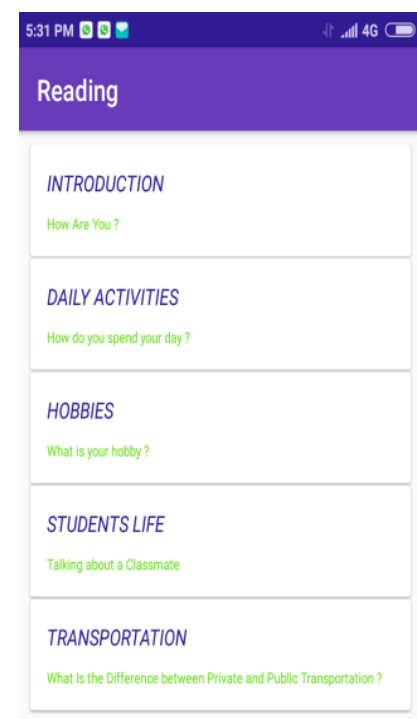

(a)

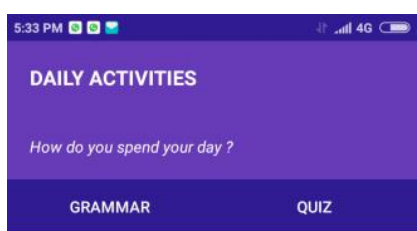

Ali : How do you spend your day, Lisa? Lisa : Well, I usually get up around five. Then I do some exercise and I take a shower, I have breakfast Ali : Really? What time do you go to campus? Lisa : I go to campus at seven. Ali : How many subjects do you have in this seven-thirty Ali : Thats cool and when do you get home? Lisa : I usually get home at four in the afternoon. Ali : What do you usually do on the weekend? Lisa : I spend my weekend by cleaning my house
and trying to cook a new recipe.

(b) Lisa : I have five subjects and all of them start at

Fig. 5. (a) Form of sub themes with category reading, (b) Form of sub themes daily activities

In listening category form, the application provides a function to play sound. Users can play the listening material with clicking the button on the right bottom of the form, as shown in the figure 6 . 


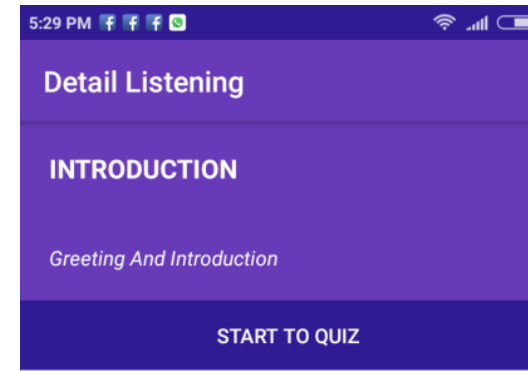

Listen. Are Mat and Sarah Friends ?

How about Rob and Sandra?

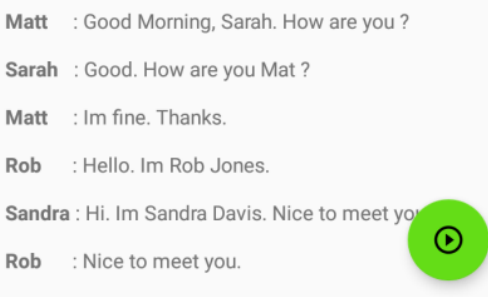

Fig. 6. Listening category form

The applications also provide quizzes for all categories in every sub themes (as shown in figure 7a). The users could check the answer by clicking the $\oplus$ button on the right bottom of the form. The system then match the users answer with the correct answer in the database and then display the result whether is correct or wrong in toast function (as shown in figure $7 \mathrm{~b}$ ), and then automatically go to the next question.
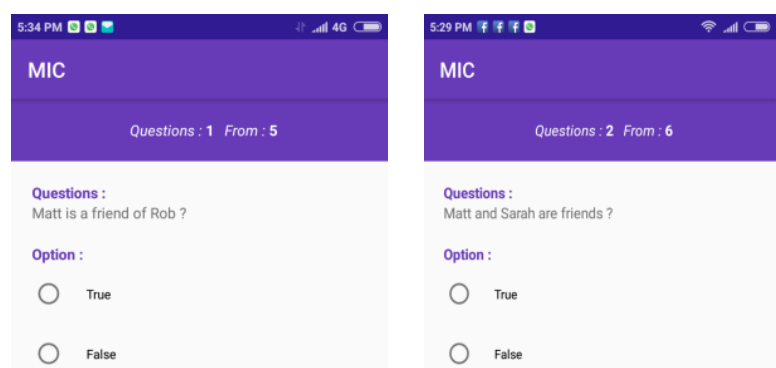

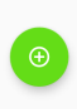

(a)

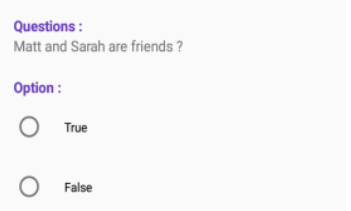

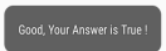

(b)
Fig. 7. (a) Form of quizzes (b) Toast function of the quiz answer

If there any changes or update to the IC materials, the users can choose the update menu, and the system will automatically update the materials (as shown in figure $8 \mathrm{a}$ and $8 \mathrm{~b}$ ).

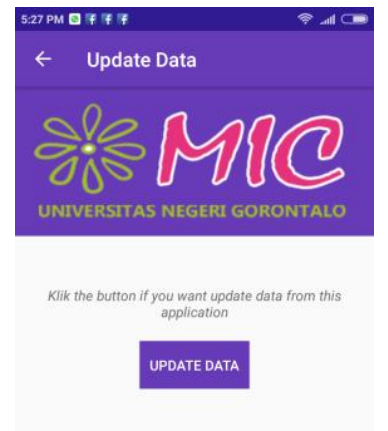

(a)

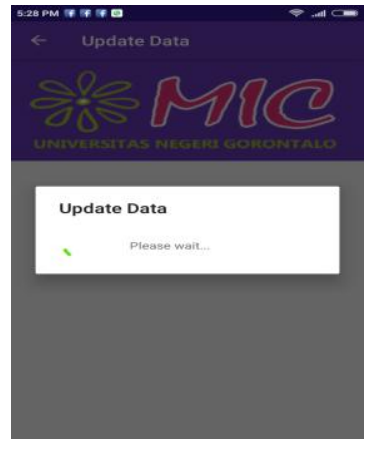

(b)
Fig. 8. (a) Update materials form, (b) Update materials process

\section{Product Validation}

After the product development phase, the next step is to validate the product with face to face discussion and try-out of the prototype application by the English IC lecturers. The result of the discussion and try-out activities is to analyze the IC materials and the design of the application, in terms of how the application could help the students to understand more easily the IC materials.

\section{Application Feedback}

This phase is to get the feedback from the students by tryout the application for 25 students of English Department. The applications then install into the students' smartphone. The steps are as follow:

1. At the beginning, the lecture explained MALL for English IC, the procedures and the features

2. Students started to apply the application

3. Lecturer taught IC material in the application and students paid attention while operating.

4. Students tried to answer every number of tasks before moving to the next one. In addition, they can see all scores after completing all tasks.

After try-out phase, questionnaire and interview were applied to the students to get their opinions and feedbacks towards the quality of application for user interface, the visualization, or the audio. The questionnaire has 9 questions applying score range for number 1 as the lowest score to number 4 as the highest one. The result showed that $88 \%$ or 22 students choose number 4 , and $12 \%$ or 3 students choose number 3 to reveal the interest in the use of application on learning the English IC. The user interface was very interesting for 10 students $(40 \%)$ marked by choosing number 4 , and 15 students $(60 \%)$ choose number 3 . There were various responds for the quality of audio. 10 students $(40 \%)$ thought it was very good by choosing number 4, 12 students (48\%) preferred number 3 and 3 students (12\%) graded number 2. Students' opinions about the scope of language skills showed that 9 students $(36 \%)$ preferred number 4 , and 16 students (64\%) answered number 3. Moreover, language components covered in this application were responded diversely. There were 10 students (40\%) choose number 4 and 15 students (60\%) preferred number 3 for responding grammar material, whereas 15 students (60\%) marked number 4 and 10 students (40\%) 
preferred number 3 for vocabulary material. For pronunciation material in the application, 12 students (48\%) chose number 4 and 13 students $(52 \%)$ chose number 3 . Students' responses towards their simplicity to comprehend IC material through application showed distinct reaction. $84 \%$ or 21 students picked number 4 and 4 students or $16 \%$ choose number 3 . Response for the advantages of the application development are 23 students (92\%) marked number 4 and 2 students (8\%) marked number 3 . The summarized of the questionnaire is shown in Table I.

TABLE I. SUMMARIZES THE STUDENTS' RESPONSES TOWARDS THE USE OF APPLICATION

\begin{tabular}{|l|l|l|l|l|l|l|}
\hline \multirow{2}{*}{ Questions } & \multicolumn{5}{c|}{ Score } \\
\cline { 2 - 8 } & \multicolumn{2}{|c|}{4} & \multicolumn{2}{c|}{3} & \multicolumn{2}{c|}{ 2 } \\
\cline { 2 - 8 } & $\begin{array}{l}\text { Students } \\
\text { amount }\end{array}$ & $\%$ & $\begin{array}{l}\text { Students } \\
\text { amount }\end{array}$ & $\%$ & $\begin{array}{c}\text { Students } \\
\text { amount }\end{array}$ & $\%$ \\
\hline $\begin{array}{l}\text { The of } \\
\text { application }\end{array}$ & 22 & 88 & 3 & 12 & & 12 \\
\hline The user interface & 10 & 40 & 12 & 60 & & \\
\hline $\begin{array}{l}\text { The quality of } \\
\text { audio }\end{array}$ & 10 & 40 & 12 & 48 & 3 & \\
\hline $\begin{array}{l}\text { The scope of } \\
\text { language skills }\end{array}$ & 9 & 36 & 16 & 64 & & \\
\hline $\begin{array}{l}\text { Grammar } \\
\text { material }\end{array}$ & 10 & 40 & 15 & 60 & & \\
\hline $\begin{array}{l}\text { Vocabulary } \\
\text { material }\end{array}$ & 15 & 60 & 10 & 40 & & \\
\hline $\begin{array}{l}\text { Pronunciation } \\
\text { material }\end{array}$ & 12 & 48 & 13 & 52 & & \\
\hline $\begin{array}{l}\text { Simplicity to } \\
\text { comprehend }\end{array}$ & 21 & 84 & 4 & 16 & & \\
\hline $\begin{array}{l}\text { advantages of the } \\
\text { application } \\
\text { development }\end{array}$ & 23 & 92 & 2 & 8 & & \\
\hline
\end{tabular}

\section{E. Application Review}

This stage is a phase to repair the application sequentially according to the application feedback from the students. The feedback then analyzed and refined to improve the quality of the application.

\section{CONCLUSION}

English IC aims to prepare the students to have a higher level of English knowledge for the next semester. The students only have two opportunities to join this program. If they fail then they have to transfer to other departments. In previous research, some researchers try to develop a WBCALL application, but this application has some limitation in the usability while moving. Students' only can run the application using laptop or desktop PC. Moreover, this WBCALL application has no ability to update it content dynamically in case of changes or updates of the materials, and it has no ability to prevent the irresponsible users. Due to these drawbacks, it is necessary to develop an application for English IC that have ability to mobile, update it content dynamically and to prevent the irresponsible users. MALL is a subset of e-learning where it deals with the use of mobile technology in language learning. The try-out of application showed that the students were very interested while using MALL application. In addition, the quality of user interface, listening audio, and the content were very good based on students' responses in questionnaire. They thought that the use of MALL in IC program were very helpful especially when they completed the tasks and quizzes. Besides, they can study not only in the classroom but also apply selfstudying outside the classroom. When they can keep practicing English using MALL inside or outside the classroom, it will definitely raise their motivation and finally increase their score of IC program.

\section{ACKNOWLEDGMENT}

This research received funding from the Ministry of Research, Technology and Higher Education of the Republic of Indonesia. The authors thank to LPPM Universitas Negeri Gorontalo for their cooperation and assistance during the research.

\section{REFERENCES}

[1] M. Rohandi, N. Husain, I.W. Bay. "Development of Web-Based Computer-Assisted Language Learning In English Intensive Course”. In: 1st Annual Applied Science and Engineering Conference (AASEC), in conjuction with The International Conference on Sport Science, Health, and Physical Education (ICSSHPE), IOP publishing Ltd. Material Science and engineering, Vol. 180, No. 1. January 2016

[2] Miangah, T. M., dan Nezarat, A. 2012. "Mobile-Asissted Language Learning". In: The International Journal of Distributed and Parallel System (IJDPS). Vol. 3. No. 1 January 2012.

[3] Huang, C., dan P. Sun. "Using mobile technologies to support mobile multimedia English listening exercises in daily life". In: The International Conference on Computer and Network Technologies in Education (CNTE 2010), At: http://cnte2010.cs.nhcue.edu.tw/

[4] Klopfer, E.; K. Squire, and H. Jenkins. "Environmental Detectives: PDAs as a window into a virtual simulated world." In: Proceedings of IEEE International Workshop on Wireless and Mobile Technologies in Education. Vaxjo, Sweden: IEEE Computer Society, pp. 95-98. 2002

[5] Kukulska-Humle, A. "Will mobile learning change language learning?" ReCALL 21(2), pp. 157-165. 2009

[6] Sugiyono. "Quantitative Qualitative research method and R\&D". Alfabeta Bandung. Bandung. 2014

[7] T A Pender. "UML Weekend Crash Course". Wiley Publishing Inc. New York. 2002

[8] A J Hoffer, J F George and J S Valacich. Modern System Analysis and Design-Third Edition, Chapter 20 Prentice-Hall Inc. 2002 